University of Nebraska - Lincoln

DigitalCommons@University of Nebraska - Lincoln

Biological Systems Engineering: Papers and

Publications

Biological Systems Engineering

2015

Flow, Spray Pattern, And Droplet Spectra Characteristics Of An Electronically Actuated Variable-Orifice Nozzle

Joe D. Luck

University of Nebraska-Lincoln, jluck2@unl.edu

Santosh Pitla

University of Nebraska-Lincoln, spitla2@unl.edu

M. P. Sama

University of Kentucky, michael.sama@uky.edu

S. A. Shearer

The Ohio State University

Follow this and additional works at: https://digitalcommons.unl.edu/biosysengfacpub

Part of the Bioresource and Agricultural Engineering Commons, Environmental Engineering Commons, and the Other Civil and Environmental Engineering Commons

Luck, Joe D.; Pitla, Santosh; Sama, M. P.; and Shearer, S. A., "Flow, Spray Pattern, And Droplet Spectra Characteristics Of An Electronically Actuated Variable-Orifice Nozzle" (2015). Biological Systems Engineering: Papers and Publications. 467.

https://digitalcommons.unl.edu/biosysengfacpub/467

This Article is brought to you for free and open access by the Biological Systems Engineering at DigitalCommons@University of Nebraska - Lincoln. It has been accepted for inclusion in Biological Systems Engineering: Papers and Publications by an authorized administrator of DigitalCommons@University of Nebraska Lincoln. 


\title{
FLOW, SPRAY PATTERN, AND DROPLET SPECTRA CHARACTERISTICS OF AN ELECTRONICALLY ACTUATED VARIABLE-ORIFICE NOZZLE
}

\author{
J. D. Luck, S. K. Pitla，M. P. Sama，S. A. Shearer
}

\begin{abstract}
The purpose of this study was to develop and evaluate the flow rate, spray pattern, and droplet spectra characteristics of an actively controlled variable-orifice nozzle at constant carrier pressures. A commercially available variable-orifice nozzle (VariTarget) was modified to allow for direct electromechanical control of the metering stem. The modified system was tested at five carrier pressures ranging from 138 to $414 \mathrm{kPa}$ and five metering stem (and thus orifice) positions. The metering stem position range was chosen because it provided a linear response in flow rate at each carrier pressure. Flow rate testing indicated a turndown ratio of 2.4:1 at each carrier pressure, with a total turndown ratio of 4.8:1 across the range of carrier pressures using the selected metering stem positions. Spray pattern testing indicated acceptable coefficients of variation for the metering stem positions and carrier pressures for nozzle spacings of 38.1 and $51.0 \mathrm{~cm}$. Droplet spectra test results showed that the particle sizes remained in the range of extremely coarse to ultra coarse for all metering stem positions and carrier pressures. Orifice control using the modified system resulted in slightly larger droplet sizes compared to the original spring-actuated nozzle; however, the potential for spray drift would be reduced. The results of this study show that active control of the VT nozzle metering stem could provide potential for improvements in pesticide application. Nozzle flow rates could be controlled via the proposed system with little negative effects on spray pattern or droplet spectra. In addition to compensating for sprayer ground speed changes, a system consisting of these nozzles could potentially be used to solve application errors generated from sprayer turning movements.
\end{abstract}

Keywords. Pesticides, Precision agriculture, Spray drift, Spraying equipment, Variable-rate application.

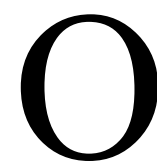
ver the past two decades, several variable-flow nozzles have been developed and tested to determine their ability to improve certain aspects of pesticide application (e.g., spray pattern and droplet spectra). Some of these nozzles studied in the past include bypass spray nozzle valves (Han et al., 1986), swirl nozzles with varying inlet openings (Koo and Kuhlman, 1993), and pinch valves ahead of the nozzle (Kunavut et al., 2000). Within the last few years, a new concept for variable-rate technology has emerged in the form of a variable-orifice design. This technology achieves variable-rate

Submitted for review in June 2014 as manuscript number MS 10798; approved for publication by the Machinery Systems Community of ASABE in January 2015.

The information reported in this article (No. 15-05-022) is part of a project of the Kentucky Agricultural Experiment Station and is published with the approval of the Director. Mention of trade names is for informational purposes only and does not necessarily imply endorsement by the Kentucky Agricultural Experiment Station.

The authors are Joe D. Luck, ASABE Member, Assistant Professor, and Santosh K. Pitla, ASABE Member, Assistant Professor, Department of Biological Systems Engineering, University of Nebraska-Lincoln, Lincoln, Nebraska; Michael P. Sama, ASABE Member, Assistant Professor, Department of Biosystems and Agricultural Engineering, University of Kentucky, Lexington, Kentucky; Scott A. Shearer, ASABE Member, Professor and Chair, Department of Food, Agricultural, and Biological Engineering, The Ohio State University, Columbus, Ohio. Corresponding author: Joe D. Luck, 206 L.W. Chase Hall, University of Nebraska-Lincoln, Lincoln, NE 68583-0726; phone: 402-472-1488; e-mail: jluck2@unl.edu. application by modifying the size and shape of the orifice. The development of this technology began in the late 1990s by Bui (1997), who tested a variable-orifice nozzle and found that flow rates and droplet spectra could both be varied. Womac (2001) evaluated the atomization characteristics of variable-orifice flood nozzles. These nozzles required external adjustment to change the orifice diameter, which would not be feasible with current technology for on-the-go modification during field application. However, the study goal was to determine the effects of varying orifice size on droplet size spectra, and the results indicated that droplet size could be modified by changing the nozzle orifice size. It was therefore determined that varying the nozzle orifice could be a method for reducing spray drift, and knowledge of the orifice diameter and liquid pressure could provide acceptable predictions of droplet spectra factors (Womac, 2001).

Design and testing of a variable-flow fan nozzle was conducted by Womac and Bui (2002). This design used a split-end metering plunger controlled by spring force in a tapered sleeve above the nozzle orifice cavity. As liquid pressure in the nozzle increased, the diaphragm applied force to the spring, which increased the orifice size by moving the plunger farther out of the sleeve. As liquid pressure decreased, the spring forced the plunger farther into the sleeve, thereby decreasing the orifice size. Test results indicated that turndown (maximum to minimum flow) ratios on the order of 13:1 were possible with this 
new design, while droplet size spectra control was possible within the range of 58 to $850 \mu \mathrm{m}$ by adjusting the spring force. Overall, the reaction of the system (spring force to liquid pressure) made it possible to control the liquid flow rate through the nozzle as well as the droplet size spectra.

A similar system (VariTarget), developed and tested by Bui (2005), used spring force to move a metering plunger in and out of an orifice based on changes in system pressure. In addition to the system previously discussed (Womac and Bui, 2002), the VariTarget (VT) nozzle included a method of adjusting the shape of the nozzle orifice as the metering plunger moved in and out of the sleeve (Bui, 2005). Testing of this nozzle indicated that as carrier pressure varied from 103 to $345 \mathrm{kPa}$, the VT nozzle flow rates ranged from 0.57 to $3.0 \mathrm{~L} \mathrm{~min}^{-1}$. Droplet sizes also varied from 325 to $425 \mu \mathrm{m}\left(\mathrm{D}_{\mathrm{v} 0.5)}\right)$ for systemic pesticides and from 200 to $240 \mu \mathrm{m}$ for contact pesticides. The spray angle and distribution of material were found to be consistent over the flow rate ranges, while the response time of the spring force to changes in liquid pressure was less than $0.25 \mathrm{~s}$. While the system developed by Bui (2005) advanced the capacity of droplet size control with variableorifice nozzles, the system was still reactive in nature, as the spring force on the metering plunger reacted to changes in pressure to control the flow rate, spray deposition pattern, and droplet size distribution.

Daggupati (2007) conducted a study of the various VT nozzles (differing caps for fine, medium, coarse, or very coarse droplet sizes) and determined that the nozzles had turndown ratios of up to 12:1. Spray pattern angle testing indicated that pressures below $207 \mathrm{kPa}$ may lead to a reduction in the spray angle $\left(110^{\circ}\right.$ target). Droplet size characteristics varied according to pressure, with droplet distribution measurements indicating that predicted ranges (fine, medium, coarse, or very coarse) may not always fall within acceptable ranges. Further tests on the VT nozzle indicated that flow rates could be maintained with a coefficient of variation $(\mathrm{CV})$ of less than $10 \%$ across the spray boom, with the optimal performance occurring at a carrier pressure of $276 \mathrm{kPa}$ and above (Dilawari et al., 2008). These studies suggest that it might be possible to achieve variable-rate application by changing system pressure (and thus low rate) using the original VT nozzle configuration. However, previous studies have indicated that controlling system pressure can be difficult as spray rate controllers attempt to compensate for ground speed changes or boom section actuation (Sharda et al., 2010; Luck et al., 2011; Sharda et al., 2011).

To create an active control method for the VT nozzle, Luck et al. (2010) modified the existing VT nozzle (green cap) by replacing the spring force with air pressure, which was varied by using an electro-pneumatic valve. Tests were conducted using constant liquid carrier pressure (69 to $276 \mathrm{kPa}$ ) while the air pressure on the diaphragm was varied to adjust the position of the metering plunger. Results indicated that flow rates ranged from $0.76 \mathrm{~L} \mathrm{~min}^{-1}(69 \mathrm{kPa}$ carrier pressure at maximum air pressure) to $6.8 \mathrm{~L} \mathrm{~min}^{-1}$ (276 $\mathrm{kPa}$ psi carrier pressure at minimum air pressure). These tests demonstrated that by maintaining the carrier pressure while varying the orifice size and shape, it was possible to achieve a wide variation of flow rates from such a nozzle configuration.

The overall goal of this research was to develop and test the operational features of an actively actuated (directoperated electromechanical) variable-orifice nozzle using constant carrier pressure. Specific project objectives were to (1) evaluate potential nozzle discharge rates, (2) determine spray pattern CV values, and (3) characterize nozzle droplet spectra within the defined operating ranges.

\section{Materials And Methods \\ VARIABLE-ORIFICE NOZZLE SETUP}

The VT variable-orifice nozzle (VariTarget, Delavan AgSpray Products, Mendota Heights, Minn.) with green cap was selected for use in this study. According to the manufacturer's data, the VT nozzle with green cap (for very coarse droplets) can be used to deliver application rates of around 93.5 $\mathrm{L} \mathrm{ha}^{-1}$ at the typical pressures (103 to $448 \mathrm{kPa}$ ) and velocities $\left(9.7\right.$ to $38.6 \mathrm{~km} \mathrm{~h}^{-1}$ ) used for many self-propelled sprayers (Delavan, 2011). The spring housing assembly was removed from the original VT nozzle and replaced with a new assembly machined to attach the plunger (original), stem, and diaphragm to an electric linear actuator. A diagram of the components necessary to adapt the VT nozzle to the linear actuator is shown in figure 1.

The stem was refabricated (drilled and tapped) so that the diaphragm could be tightly sealed at the metering stem (combined plunger and stem) top with the threaded extension rod. The metering stem was forced downward to decrease the orifice size and reduce the nozzle flow rate, which was similar in operation to the original VT nozzle. As the metering stem was retracted (upward), the orifice size increased to allow higher discharge rates. The VT nozzle assembly was attached to a single nozzle body (22251311-750-NYB, TeeJet Technologies, Wheaton, Ill.) with $19 \mathrm{~mm}$ i.d. hose connecting the system components.

A linear actuator (NA14B16, Zaber Technologies, Inc., Vancouver, British Columbia, Canada) was selected to actuate and control the metering stem position for the modified VT nozzle. The end of the actuator rod was threaded into the extension rod. A stepper-motor controller (STP100, Pontech, Rancho Cucamonga, Cal.) was used to control the

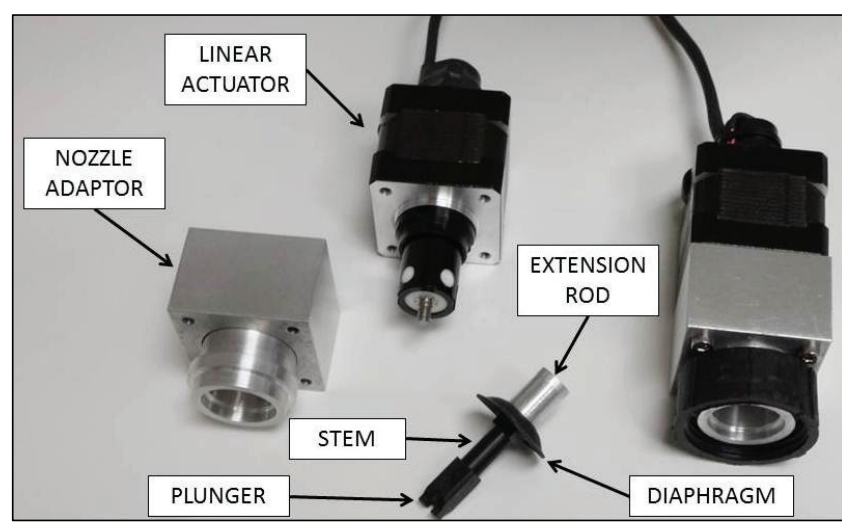

Figure 1. Components of adapted VT nozzle used for testing. 


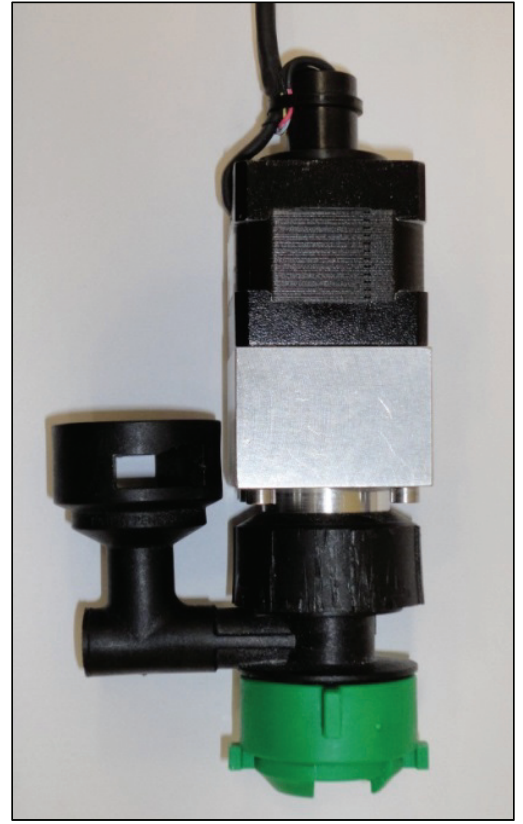

Figure 2. Assembled nozzle prior to attachment to nozzle body.

linear actuator position. A simple program was written using Microsoft Visual Studio 2010 to position the linear actuator via commands sent to the stepper-motor controller through the computer serial/USB port. The software provided manual control of the linear actuator whereby the desired metering stem position in motor steps (MS) was entered into the user interface. The position of the actuating rod was directly proportional to MS. Operational setup of the stepper-motor controller included a step delay of $800 \mu \mathrm{s}$ with power constantly supplied to the motor coils during operation per the manufacturer's specifications (Pontech, 1997). The fully assembled modified VT nozzle system, which allowed for attachment to the nozzle body, is shown in figure 2.

Carrier flow was supplied by a smooth-flow helical rotor pump (101B, Oberdorfer Pumps, Syracuse, N.Y.) driven by a $0.75 \mathrm{hp} 115 \mathrm{~V}$ motor operating at $1725 \mathrm{rpm}$. Carrier pressure was controlled with a pressure regulating (PR) valve (model 23120, TeeJet Technologies, Wheaton, Ill.). Carrier pressure was constantly monitored using a calibrated pressure transducer (PX309-100G5V, Omegadyne, Inc., Sunbury, Ohio) that supplied a 0 to 5 VDC output signal proportional to system pressure. A digital multimeter (117, Fluke Corp., Everett, Wash.) was used to monitor the out- put of the pressure sensor to ensure a working pressure within $\pm 2 \%$ of the desired system pressure during testing per ASTM Standard E641-01 (ASTM, 2006). System flow rate was monitored using an electromagnetic flowmeter (EFM) with a digital display (FMG202-NPT, Omega Engineering, Inc., Stamford, Conn.). An 80-mesh inline filter (39908-1, Delavan AgSpray Products, Mendota Heights, Minn.) was placed in the circuit between the reservoir and pump. A diagram of the system is shown in figure 3.

\section{Nozzle Flow Rate Testing}

All nozzle flow rate and spray pattern tests were performed in accordance with ASTM Standard E641-01 for testing hydraulic spray nozzles used in agriculture (ASTM, 2006). The EFM was calibrated according to Section 6.2.3 of ASTM Standard E641-01 and was found to have an error of less than $0.5 \%$ in the flow readings over the range of sensitivity $\left(0.5\right.$ to $\left.3.0 \mathrm{~L} \mathrm{~min}^{-1}\right)$. The metering stem was adjusted from the open position (linear actuator fully retracted) to the closed position (linear actuator extended), which corresponded to 0 to $800 \mathrm{MS}$, respectively. The maximum nozzle flow rate was achieved at $0 \mathrm{MS}$, and the minimum nozzle flow rate was achieved at 800 MS. Since the system was operated in an open-loop configuration, it was necessary to begin each test at the 0 MS position as an initialization step. Flow rates were collected at increasing intervals of 100 steps.

Five carrier pressures ranging from 138 to $414 \mathrm{kPa}$, which fell within the operating range for the VT nozzle, were selected for flow rate and spray pattern testing. As the linear actuator was extended at 100-step intervals, the carrier pressure was adjusted to achieve the desired pressure by observing the pressure transducer output on the digital multimeter. As the metering stem was extended to the correct position, the carrier pressure was decreased to the desired test pressure via the PR valve. Alternately, as the metering stem was retracted, the pressure was increased to the test pressure. This process was repeated three times for each carrier test pressure. Flow rates and pressure sensor readings were recorded at each instance, for a total of six measurements for each carrier test pressure and metering stem position.

The flow rates were plotted versus the metering stem position to observe the nozzle discharge characteristics. Trendlines were plotted for these data to verify if the flow rates could be considered to vary linearly as the metering stem was actuated. To further evaluate linear models for

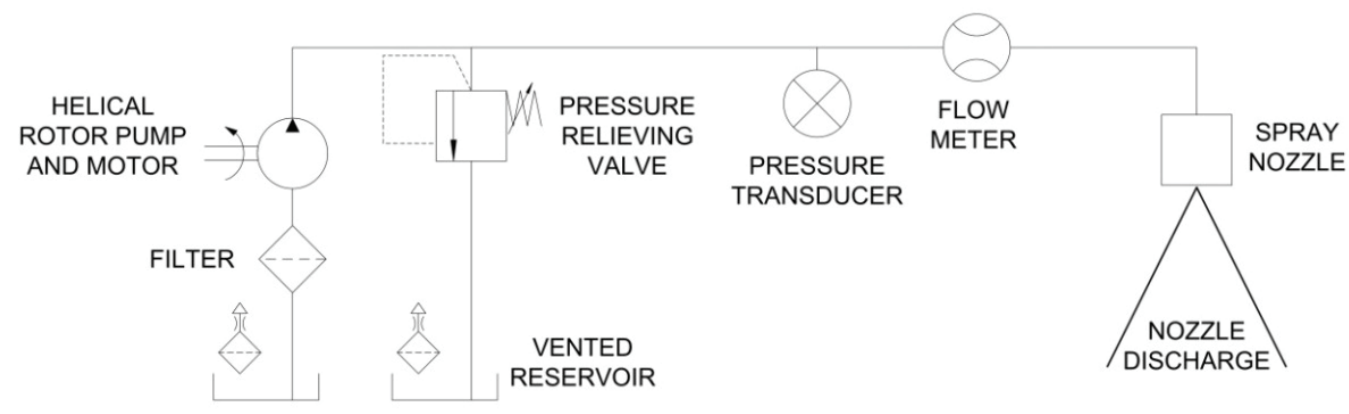

Figure 3. System schematic for flow rate, spray pattern, and droplet spectra testing. 
predicting nozzle flow rate from metering stem position, the standard error (SE) was calculated from Haan (2002) using equation 1 :

$$
\mathrm{SE}=\frac{\sum\left(Y_{i}-\hat{Y}_{i}\right)^{2}}{n-2}
$$

where

$Y_{i}=$ measured flow rate $\left(\mathrm{L} \min ^{-1}\right)$

$\hat{Y}_{i}=$ estimated flow rate from regression $\left(\mathrm{L} \mathrm{min}^{-1}\right)$

$n=$ number of samples.

The coefficient of variation (CV) was calculated from Haan (2002) using equation 2:

$$
\mathrm{CV}=\frac{\mathrm{SE}}{\bar{y}}
$$

where $\bar{y}$ is the average measured flow rate $\left(\mathrm{L} \mathrm{min}^{-1}\right)$.

The turndown ratio for a given set of operating parameters was calculated as an average of the maximum flow rate divided by the minimum flow rate for each data point. MATLAB (R2012a, MathWorks, Natick, Mass.) was used to generate three-dimensional plots of flow rate versus metering stem position and carrier pressure to better illustrate their effects on flow rate. This MATLAB function (surface) was also used to plot spray pattern and droplet spectra results versus metering stem position and carrier pressure.

\section{Nozzle SPRAy PatTern Testing}

A spray pattern testing stand was fabricated to divide the nozzle discharge into sixty-one $2.5 \mathrm{~cm}$ wide troughs across the spray pattern. The troughs were centered beneath the spray nozzle at a distance of $48.3 \mathrm{~cm}$. The effluent from each trough was collected in $25 \mathrm{~mL}$ graduated cylinders with $0.5 \mathrm{~mL}$ subdivisions; therefore, measurements to the nearest $0.25 \mathrm{~mL}$ were taken. Spray pattern tests were conducted according to Section 6.4.3 of ASTM Standard E64101, which outlines procedures for the volume-time method. At each metering stem position and carrier pressure position, three sets of data were recorded: test pressure, test time, and volume from each graduated cylinder. Data were collected for five carrier pressures at intervals of 100 steps from 400 to $800 \mathrm{MS}$.

To normalize the volume of carrier collected, the volume of each graduated cylinder was divided by the maximum single-tube volume collected during each test run. The resulting distribution was then superimposed $38.1 \mathrm{~cm}$ (15.0 in.) and $51.0 \mathrm{~cm}$ (20.0 in.) left and right, respectively, of the center nozzle. This provided a more realistic distribution of data across the spray pattern, as these spacings were recommended by the nozzle manufacturer (Delavan, 2011). The normalized discharge values for the three nozzle distributions were then summed within the range of 51.0 (or $38.1) \mathrm{cm}$ for the center nozzle. This method, following from Ozkan et al. (1992), provided a simulated distribution that would occur for a nozzle spacing of 38.1 or $51.0 \mathrm{~cm}$ across the spray boom. The resulting values within this range were used to calculate the average and standard error among the normalized discharge values. The results provided three $\mathrm{CV}$ values for each metering stem position and carrier test pressure, which were then averaged for a final spray pattern CV estimate. Average spray pattern CVs were plotted versus metering stem position and carrier pressure.

Statistical analyses were conducted using SAS software to determine if there were significant differences in spray pattern CVs resulting from carrier pressure or metering stem positions. The analyses utilized a two-tailed least significant difference tests; significance was evaluated based on an alpha value of 0.05 .

\section{Nozzle Droplet SPeCTRA TESTING}

Droplet spectra tests were performed in accordance with ASABE Standard S572.1, which provides standard methods for spray nozzle classification by droplet spectra (ASABE, 2009). Six nozzles were used to develop the droplet spectra division lines, ranging from $\mathrm{VF} / \mathrm{F}$ to $\mathrm{XC} / \mathrm{UC}$ according to ASABE Standard S572.1 (XR11001, XR11003, XR11006, XR11008, XR11010, and XR11015, TeeJet Technologies, Wheaton, Ill.). Testing was conducted at the Ohio State University using a laser diffraction particle analyzer (2600, Malvern, Worcestershire, U.K.) with a $600 \mathrm{~mm}$ lens. The nozzle was set at a height of $20.3 \mathrm{~cm}(8$ in.) above the laser beam. The carrier delivery system used during the droplet spectra testing was identical to the flow rate and spray pattern tests (fig. 3).

The data collection process began with taking a background light reading with the nozzle off. The pump was turned on, and the metering stem was adjusted to the desired position at 100-step intervals from 400 to $800 \mathrm{MS}$. Finally, the PR valve was adjusted to the desired test pressures (ranging from 138 to $414 \mathrm{kPa}$ ) by observing the pressure sensor output. Data acquisition began as the nozzle was passed across the laser beam to take readings across the full spray pattern with a positioner (Unislide 8000, Velmex, Inc., Bloomfield, N.Y.). When the spray pattern had fully passed the laser beam, data collection was stopped and the pump was turned off. The testing order was conducted such that metering stem adjustments were made from 400 to $800 \mathrm{MS}$ for one carrier pressure setting. The carrier pressure was then increased, and the tests were repeated three times for the desired metering stem positions. The resulting cumulative volume fraction values $\left(D_{v 0.1}\right.$, $\mathrm{D}_{\mathrm{v} 0.5}$, and $\mathrm{D}_{\mathrm{v} 0.9}$ ) were recorded from the computer output and averaged to estimate the final values. The droplet sizes (microns) were plotted versus the cumulative volume fraction according to ASABE Standard S571.2 to observe the effects of metering stem position on nozzle droplet spectra at the carrier test pressures. Average volume mean diameter $\left(D_{v 0.5}\right)$ values were plotted versus metering stem position and carrier pressure. Statistical analyses were conducted using SAS (ver. 9.3, SAS Institute, Inc., Cary, N.C.) to determine if there were significant differences in $\mathrm{D}_{\mathrm{v} 0.5}$ values from carrier pressure or metering stem positions. The analyses utilized a two-tailed least significant difference tests evaluated based on an alpha value of 0.05 . The relative span (RS) was calculated for each combination of metering stem and carrier pressure using the average of the three replicates for $D_{v 0.1}, D_{v 0.5}$, and $D_{v 0.9}$ values using equation 3 :

$$
\mathrm{RS}=\left(\mathrm{D}_{\mathrm{v} 0.9}-\mathrm{D}_{\mathrm{v} 0.1}\right) / \mathrm{D}_{\mathrm{v} 0.5}
$$




\section{RESULTS AND DISCUSSION}

NozzLE FLOW RATE

Initial flow rate results indicated that the nozzle output was not linear with respect to metering stem position across the full range of MS (0 to 800). The metering stem was not in contact with the nozzle orifice when fully retracted. As the actuator was extended past $300 \mathrm{MS}$, the metering stem began to affect the nozzle orifice, and a decrease in nozzle flow rate was noticed. Figure 4 shows nozzle flow rate versus metering stem position at a carrier pressure of $138 \mathrm{kPa}$. Initial tests determined that there was little or no effect on nozzle flow rate when the metering stem was displaced farther than 800 MS. Therefore, the maximum metering stem position was considered to be $800 \mathrm{MS}$ to ensure there was no damage to the nozzle tip. The minimum position for future tests was chosen as 400 MS to remain within this linear operating range. System response is important from a control theory perspective. The nozzle flow rate response was essentially linear for metering stem positions ranging from 400 to $800 \mathrm{MS}$. A trendline is included in figure 4 for this region where the flow rate response was linear. The result was a 2.4:1 turndown ratio from 400 to 800 MS. Based on these preliminary data, flow rate, spray pattern, and droplet spectra tests were performed within the linear response range (400 to 800 steps) of the nozzle.

Figure 5 shows the flow rate versus metering stem position at five operating pressures. Trendlines fit to these data highlight the linearity of flow rate response to metering stem adjustments. The $\mathrm{R}^{2}$ values were above 0.99 for all five carrier pressures, while model SE values ranged from 0.03 to $0.08 \mathrm{~L} \mathrm{~min}^{-1}$. There were minor flow rate variations with respect to metering stem position, as indicated by the low CV values (1.7\% to $2.5 \%)$ shown in figure 5 . Results indicated that turndown ratios within each operating pressure averaged 2.4:1, while the maximum turndown across all pressures was approximately $4.8: 1$. Therefore, flow rates ranging from 4.14 to $0.86 \mathrm{~L} \mathrm{~min}^{-1}$ were achieved by varying the carrier pressure (138 to $414 \mathrm{kPa}$ ) and metering stem position (400 to $800 \mathrm{MS}$ ). These values indicated that the variable-orifice nozzle operating across these pressure values exhibited effective orifice sizes ranging from an 02 $(800 \mathrm{MS}$ at $138 \mathrm{kPa})$ to an $08(400 \mathrm{MS}$ at $414 \mathrm{kPa})$. Figure 6 shows nozzle flow rate versus metering stem position and carrier pressure. Thus, potential nozzle flow rates are visible for different combinations of metering stem position and carrier pressure.

This information highlights the fact that while only a limited number of positions may be useful for achieving minimum and maximum flow rates, multiple carrier pressure and metering stem position combinations were available for mid-range flows ( 2 to $3 \mathrm{~L} \mathrm{~min}^{-1}$ ). As previously discussed, modifying the nozzle flow rate was possible by adjusting the metering stem position. Based on these data, a system capable of carrier pressure and metering stem position control would provide a wider range of flow rates. Both variables were significant to the model $(p<0.0001)$ at the $95 \%$ confidence level. The adjusted $\mathrm{R}^{2}$ of 0.98 for the equation indicated a good fit, and the overall model SE was $0.125 \mathrm{~L} \mathrm{~min}^{-1}$. Nozzle flow rates were calculated by inputting carrier pressure and metering stem position test values into equation 4.

Multiple regression yielded equation 4 for flow rate versus metering stem position (in motor steps) and carrier pressure:

Flow rate $\left(\mathrm{L} \mathrm{min}^{-1}\right)=-0.0045 \mathrm{MS}+0.0058 P+3.34$

where $M S$ is metering stem position (motor steps), and $P$ is carrier pressure $(\mathrm{kPa})$.

\section{NOZZle SPRAY PATTERN}

The variations (average of three test runs) in spray pattern distribution (51.0 $\mathrm{cm}$ spacing) are summarized in table 1. Spray pattern CVs were less than $10 \%$ within the selected nozzle operating range (metering stem position from 400 to $800 \mathrm{MS}$ ) for carrier pressures ranging from 138 to $414 \mathrm{kPa}$. Ozkan et al. (1992) and Azimi et al. (1985)

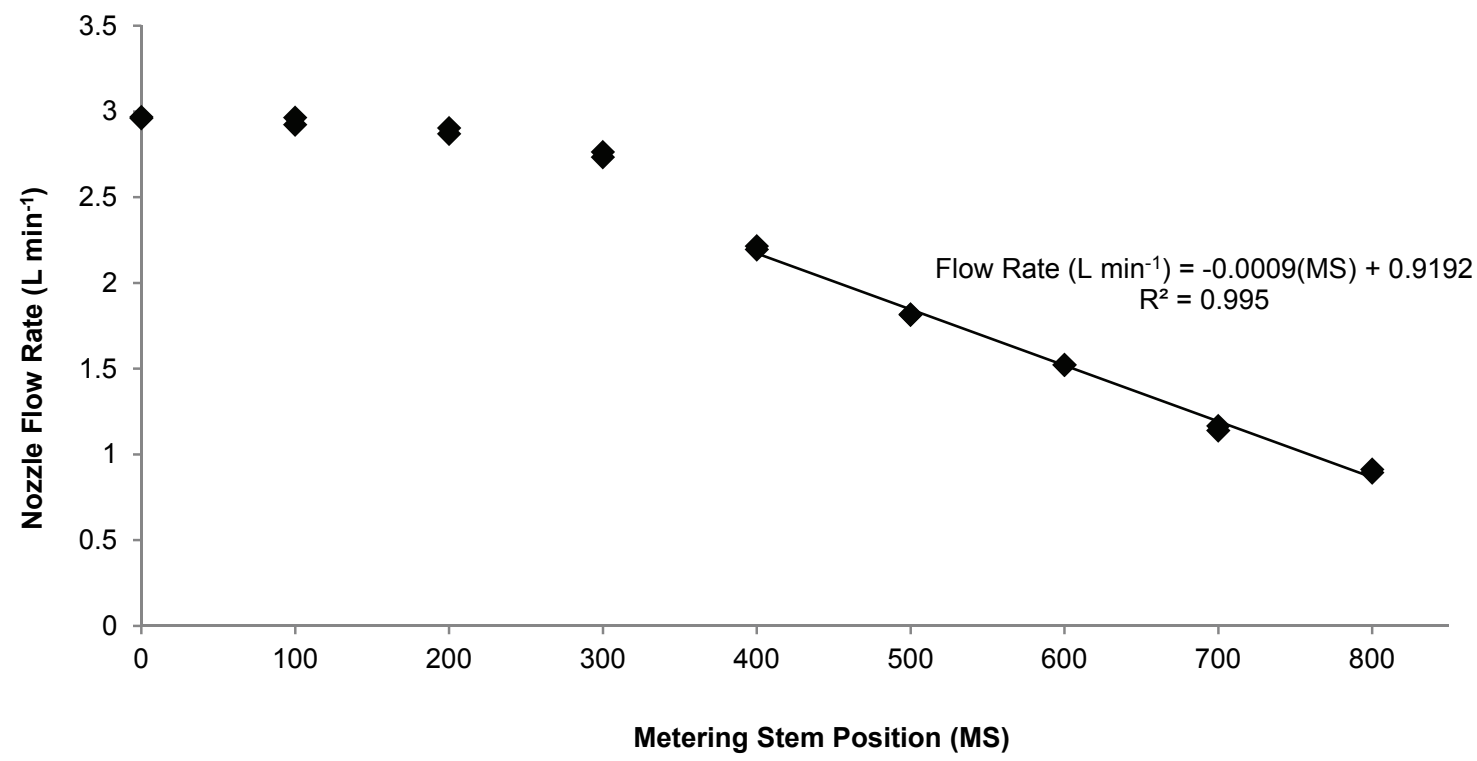

Figure 4. Nozzle flow rate (at $138 \mathrm{kPa}$ ) versus metering stem position for full range of linear actuator. 


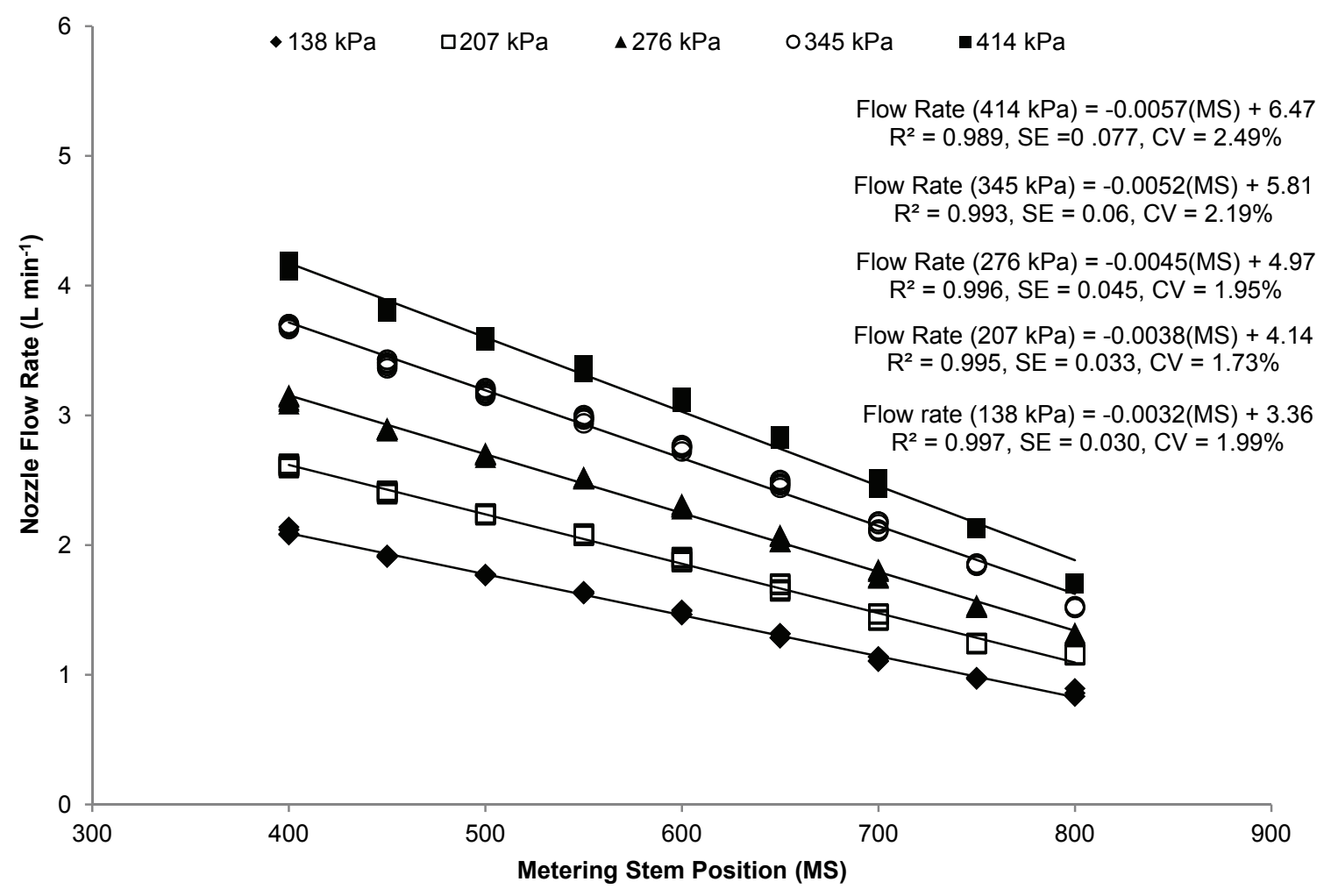

Figure 5. Nozzle flow rate versus metering stem position at five operating pressures.

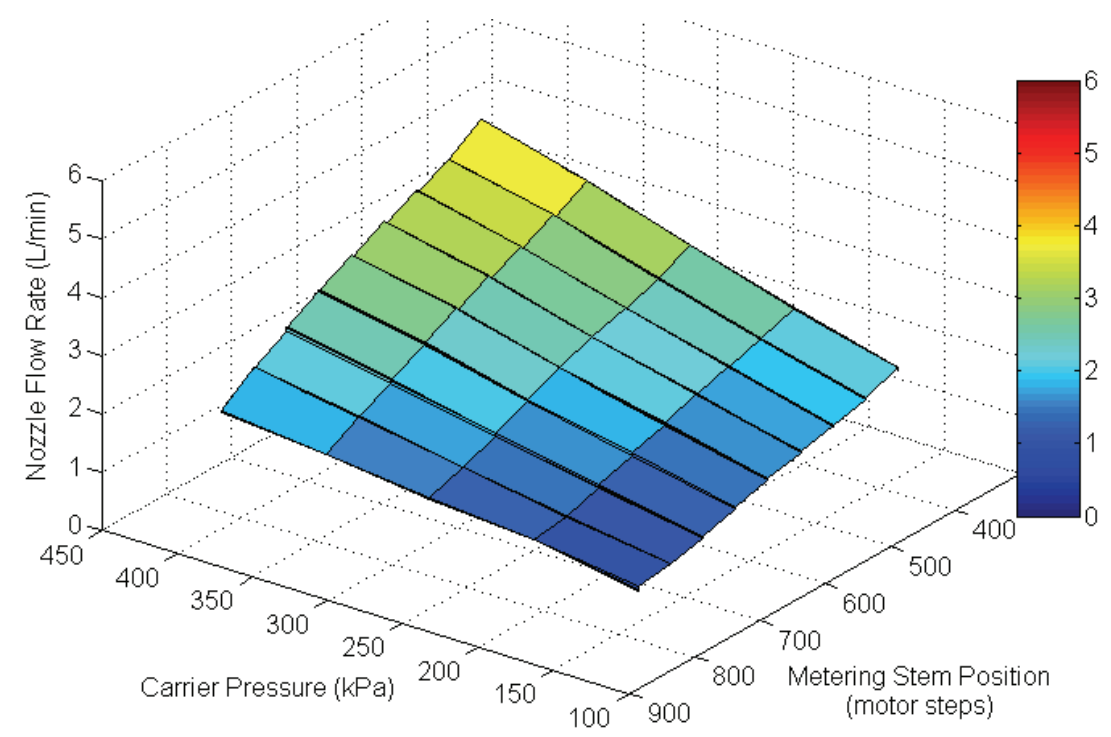

Figure 6. 3D plot of flow rate data versus metering stem position and carrier pressure.

indicated that $\mathrm{CV}$ values for spray patterns below $10 \%$ were desirable, while CVs less than $15 \%$ were regarded as acceptable. All CV values for spray distribution were therefore found to be acceptable. There was no consistent trend in the spray pattern CVs resulting from changes in metering stem position. Higher carrier pressures tended to yield slightly lower spray pattern $\mathrm{CV}$ values, while mid-range metering stem positions (500 to $600 \mathrm{MS}$ ) yielded the lowest average CVs. Therefore, spray pattern CVs could be improved by operating the nozzle at higher pressures or at mid-range metering stem positions.

Spray pattern distribution data resulting from three tests are shown in figure 7 . The tests were conducted with a carrier pressure of $207 \mathrm{kPa}$ with the metering stem positioned at $600 \mathrm{MS}$. This distribution represented the lowest (most desirable) spray pattern CV (1.85\%) for the data collected.

Utilizing the same distribution data, the nozzle spacing was shifted from 51.0 to $38.1 \mathrm{~cm}$ for analysis of the spray pattern at the narrower spacing. Spray pattern CVs are summarized in table $2(38.1 \mathrm{~cm}$ spacing). Results were mixed, as the narrower spacing produced lower CVs for most carrier pressure and metering stem combinations. Narrowing the nozzle spacing resulted in acceptable spray pattern CVs $(<10 \%)$ for all carrier pressures and metering 
Table 1. Spray pattern CV values $(51.0 \mathrm{~cm}$ spacing) at five carrier pressures and metering stem positions. ${ }^{\text {[a] }}$

\begin{tabular}{|c|c|c|c|c|c|c|}
\hline \multirow{3}{*}{$\begin{array}{c}\text { Carrier } \\
\text { Pressure } \\
(\mathrm{kPa})\end{array}$} & \multicolumn{6}{|c|}{ Average Spray Pattern CV (\%) } \\
\hline & \multicolumn{6}{|c|}{ Metering Stem Position (MS) } \\
\hline & 400 & 500 & 600 & 700 & 800 & Average \\
\hline 138 & 6.80 & 3.79 & 3.41 & 7.52 & 6.39 & $5.58 \mathrm{~A}$ \\
\hline 207 & 6.21 & 2.54 & 1.85 & 6.58 & 5.77 & $4.87 \mathrm{~A}$ \\
\hline 276 & 4.31 & 2.43 & 2.59 & 7.28 & 7.76 & $4.59 \mathrm{AB}$ \\
\hline 345 & 3.39 & 2.74 & 2.47 & 2.69 & 5.75 & $3.39 \mathrm{BC}$ \\
\hline 414 & 2.32 & 3.42 & 2.71 & 2.60 & 4.24 & $3.05 \mathrm{C}$ \\
\hline Average & $4.60 \mathrm{~b}$ & $2.98 \mathrm{c}$ & $2.60 \mathrm{c}$ & $5.33 \mathrm{ab}$ & $5.97 \mathrm{a}$ & - \\
\hline
\end{tabular}

stem positions that were tested.

There was no significant difference $(\mathrm{p}>0.05)$ in spray pattern variation for nozzle spacings of 38.1 or $51.0 \mathrm{~cm}$. Improvements may be possible at certain combinations of pressure and metering stem positions by changing the nozzle spacing. However, one noteworthy finding was that if there was no significance in spray pattern CVs, application rates could be varied by changing the nozzle spacing. Operating the nozzles at $38.1 \mathrm{~cm}$ would allow higher application rates at a particular ground speed, which may be important for achieving a desired rate.

\section{DROPLET SPECTRA}

Table 3 contains a summary of average $D_{v 0.5}$ values with the statistical analysis results to observe the effects of carrier pressure (i.e., treatment) on $\mathrm{D}_{\mathrm{v} 0.5}$ values. As a point of note, the green cap selected for the nozzle tested was reported by the manufacturer to deliver very coarse droplets; however, the data collected here showed extremely coarse and ultra coarse droplet sizes. These data indicate that, as the carrier pressure increased, the average $\mathrm{D}_{\mathrm{v} 0.5}$ decreased at each metering stem position. The decrease in $D_{\mathrm{v} 0.5}$ was more pronounced at lower metering stem positions. As the metering stem position increased, there were fewer divisions among different carrier pressures; however, significant differences still existed among $\mathrm{D}_{\mathrm{v} 0.5}$ values in each group. Droplet spectra classification values for the metering
Table 2. Spray pattern $\mathrm{CV}$ values $(38.1 \mathrm{~cm}$ spacing) at different carrier pressure and metering stem positions. ${ }^{[a]}$

\begin{tabular}{ccccccc}
\hline Carrier & \multicolumn{6}{c}{ Average Spray Pattern CV (\%) } \\
\cline { 2 - 7 } $\begin{array}{c}\text { Pressure } \\
(\mathrm{kPa})\end{array}$ & 400 & 500 & 600 & 700 & 800 & Average \\
\hline 138 & 2.74 & 3.11 & 2.31 & 9.00 & 7.22 & $4.88 \mathrm{~A}$ \\
207 & 2.30 & 3.07 & 2.28 & 5.71 & 9.16 & $4.50 \mathrm{AB}$ \\
276 & 2.44 & 2.54 & 2.78 & 5.02 & 6.50 & $3.86 \mathrm{AB}$ \\
345 & 2.42 & 2.28 & 2.28 & 3.36 & 5.62 & $3.19 \mathrm{~B}$ \\
414 & 5.07 & 1.92 & 2.44 & 2.78 & 4.60 & $3.36 \mathrm{AB}$ \\
\hline Average & $2.99 \mathrm{c}$ & $2.59 \mathrm{c}$ & $2.42 \mathrm{c}$ & $5.17 \mathrm{~b}$ & $6.62 \mathrm{a}$ & - \\
\hline
\end{tabular}

[a] Capital letters indicate significant difference in average $\mathrm{CV}$ values for carrier pressure, and lowercase letters indicate significant difference in average $\mathrm{CV}$ values for metering stem position ( $\mathrm{p} \leq 0.05)$.

stem positions and carrier pressures are also shown in table 3. These data show that droplet spectra were affected by changes in carrier pressure and metering stem position. As expected, smaller particle sizes were produced from the nozzle as carrier pressure increased. However, droplet spectra values were all classified as extremely coarse to ultra coarse. This result indicates that the potential for spray drift would be low across these operating pressures due to larger droplet sizes with this configuration.

The effects of metering stem position (i.e., treatment) on $\mathrm{D}_{\mathrm{v} 0.5}$ for the five carrier pressures are summarized in table 4. Unlike carrier pressure, metering stem position did not have a consistent effect on droplet spectra as the position was increased or decreased. For instance, there was no significant difference among the $\mathrm{D}_{\mathrm{v} 0.5}$ values at $138 \mathrm{kPa}$ as the metering stem position changed. While significant differences were noticed in average $\mathrm{D}_{\mathrm{v} 0.5}$ values, there was no clear trend in these data with respect to metering stem position. RS values calculated across the metering stem positions and carrier pressures ranged from 1.36 to 1.7 , varying approximately $10 \%$ about the mean RS of 1.52 . These values were comparable to what others have found for nozzles ranging from 02 to 04 in size (Czaczyk, 2012) and suggests relatively low variation across the operating envelop in droplet size distributions.

Average $D_{\mathrm{v} 0.5}$ values are plotted versus carrier pressure and metering stem position in figure 8 . These data highlight

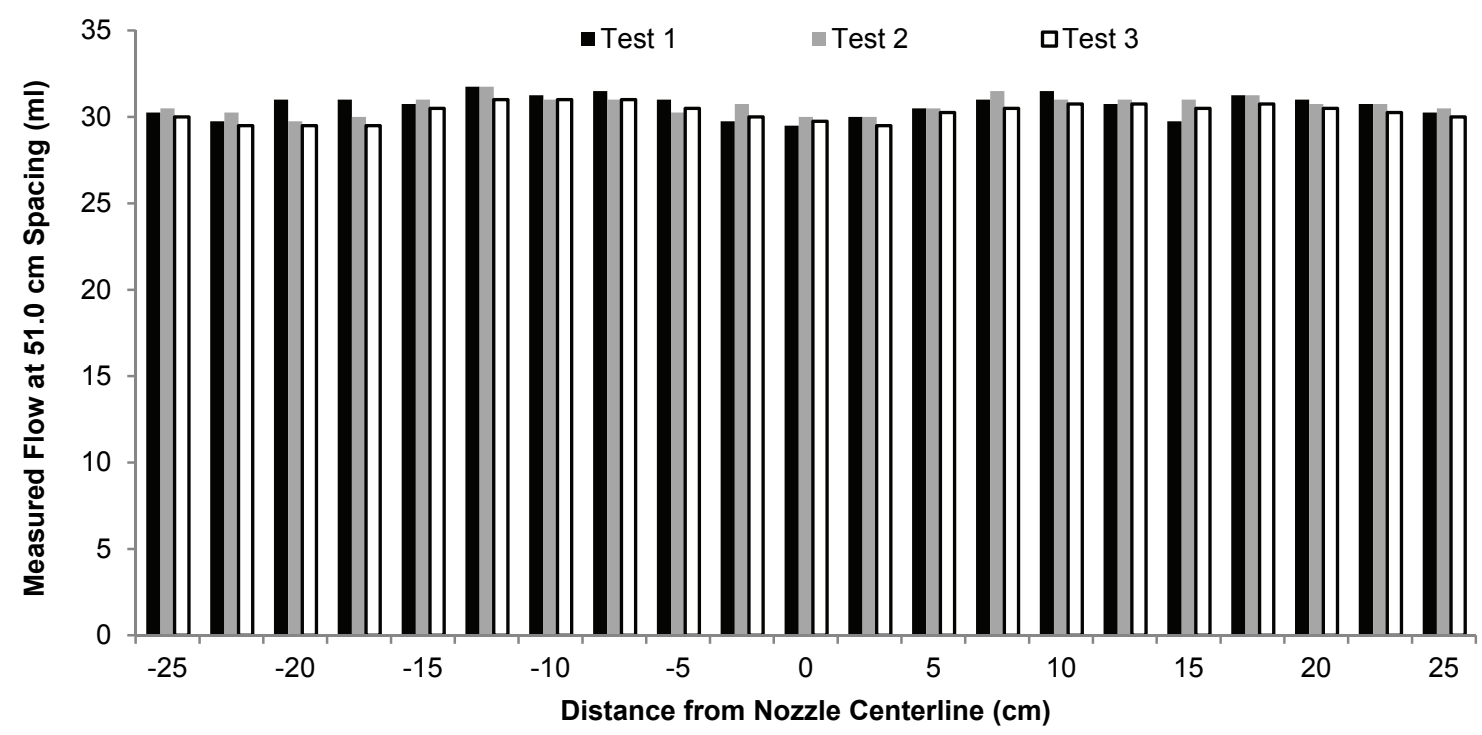

Figure 7. Spray pattern distribution at $207 \mathrm{kPa}$ and a metering stem position of $600 \mathrm{MS}$. 
Table 3. Effects of carrier pressure on $D_{\mathrm{v} 0.5}$ at five metering stem positions based on statistical analysis with corresponding droplet spectra classifications. ${ }^{\text {a] }}$

\begin{tabular}{|c|c|c|c|c|c|c|}
\hline \multirow{3}{*}{\multicolumn{2}{|c|}{$\begin{array}{c}\text { Carrier } \\
\text { Pressure } \\
(\mathrm{kPa})\end{array}$}} & \multicolumn{5}{|c|}{$\begin{array}{c}\text { Average } \mathrm{D}_{\mathrm{v} 0.5} \text { (microns) } \\
\text { [Droplet Spectra Classification Category }\end{array}$} \\
\hline & & \multicolumn{5}{|c|}{ Metering Stem Position (MS) } \\
\hline & & 800 & 700 & 600 & 500 & 400 \\
\hline \multirow{2}{*}{\multicolumn{2}{|c|}{138}} & $511 \mathrm{~A}$ & $538 \mathrm{~A}$ & $505 \mathrm{~A}$ & $515 \mathrm{~A}$ & $535 \mathrm{~A}$ \\
\hline & & {$[\mathrm{UC}]$} & {$[\mathrm{UC}]$} & {$[\mathrm{UC}]$} & [UC] & [UC] \\
\hline \multirow{2}{*}{\multicolumn{2}{|c|}{207}} & $447 \mathrm{~B}$ & $466 \mathrm{~B}$ & $441 \mathrm{~B}$ & $453 \mathrm{~B}$ & $487 \mathrm{~B}$ \\
\hline & & {$[\mathrm{XC}]$} & [UC] & [UC] & [UC] & [UC] \\
\hline \multirow{2}{*}{\multicolumn{2}{|c|}{276}} & $405 \mathrm{C}$ & $422 \mathrm{C}$ & $399 \mathrm{C}$ & $428 \mathrm{BC}$ & $460 \mathrm{BC}$ \\
\hline & & {$[\mathrm{XC}]$} & {$[\mathrm{XC}]$} & {$[\mathrm{XC}]$} & [UC] & [UC] \\
\hline \multirow{2}{*}{\multicolumn{2}{|c|}{345}} & $378 \mathrm{D}$ & $388 \mathrm{D}$ & $373 \mathrm{CD}$ & $381 \mathrm{CD}$ & $436 \mathrm{C}$ \\
\hline & & {$[\mathrm{XC}]$} & {$[\mathrm{XC}]$} & {$[\mathrm{XC}]$} & {$[\mathrm{XC}]$} & [UC] \\
\hline \multirow{2}{*}{\multicolumn{2}{|c|}{414}} & $364 \mathrm{D}$ & $372 \mathrm{D}$ & $349 \mathrm{D}$ & $395 \mathrm{D}$ & $416 \mathrm{C}$ \\
\hline & & {$[\mathrm{XC}]$} & {$[\mathrm{XC}]$} & {$[\mathrm{XC}]$} & {$[\mathrm{XC}]$} & {$[\mathrm{XC}]$} \\
\hline \multirow{2}{*}{\multicolumn{2}{|c|}{ b }} & & $\begin{array}{l}\text { ignif } \\
05) .\end{array}$ & feren & erage & values \\
\hline & & nety & 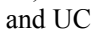 & 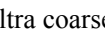 & & \\
\hline
\end{tabular}

Table 4. Effects of metering stem position on $D_{v 0.5}$ at five carrier pressures based on statistical analysis with RS values calculated from equation 3. ${ }^{[a]}$

\begin{tabular}{cccccc}
\hline \multirow{2}{*}{$\begin{array}{c}\text { Metering } \\
\text { Stem } \\
\text { Position } \\
(\mathrm{MS})\end{array}$} & \multicolumn{5}{c}{$\begin{array}{c}\text { Average } \mathrm{D}_{\mathrm{v} 0.5} \text { (microns) } \\
\text { [Relative Span] }\end{array}$} \\
\cline { 2 - 6 } & 138 & 207 & 276 & 345 & 414 \\
\cline { 2 - 6 } 400 & $535 \mathrm{~A}$ & $487 \mathrm{~A}$ & $460 \mathrm{~A}$ & $436 \mathrm{~A}$ & $416 \mathrm{~A}$ \\
& {$[1.47]$} & {$[1.52]$} & {$[1.50]$} & {$[1.51]$} & {$[1.47]$} \\
\hline \multirow{2}{*}{500} & $515 \mathrm{~A}$ & $453 \mathrm{BC}$ & $428 \mathrm{AB}$ & $381 \mathrm{~B}$ & $395 \mathrm{AB}$ \\
& {$[1.51]$} & {$[1.53]$} & {$[1.55]$} & {$[1.70]$} & {$[1.6]$} \\
\hline \multirow{2}{*}{600} & $505 \mathrm{~A}$ & $441 \mathrm{C}$ & $399 \mathrm{~B}$ & $373 \mathrm{~B}$ & $349 \mathrm{C}$ \\
& {$[1.52]$} & {$[1.54]$} & {$[1.61]$} & {$[1.56]$} & {$[1.56]$} \\
\hline \multirow{2}{*}{700} & $538 \mathrm{~A}$ & $466 \mathrm{AB}$ & $422 \mathrm{~B}$ & $388 \mathrm{~B}$ & $372 \mathrm{BC}$ \\
& {$[1.44]$} & {$[1.48]$} & {$[1.49]$} & {$[1.66]$} & {$[1.51]$} \\
\hline \multirow{2}{*}{800} & $511 \mathrm{~A}$ & $447 \mathrm{BC}$ & $405 \mathrm{~B}$ & $378 \mathrm{~B}$ & $364 \mathrm{BC}$ \\
& {$[1.48]$} & {$[1.41]$} & {$[1.54]$} & {$[1.36]$} & {$[1.37]$} \\
\hline [a] Capital letters indicate significant difference in average $\mathrm{D}_{\mathrm{v} 0.5}$ values for
\end{tabular}
metering stem positions $(\mathrm{p} \leq 0.05)$.

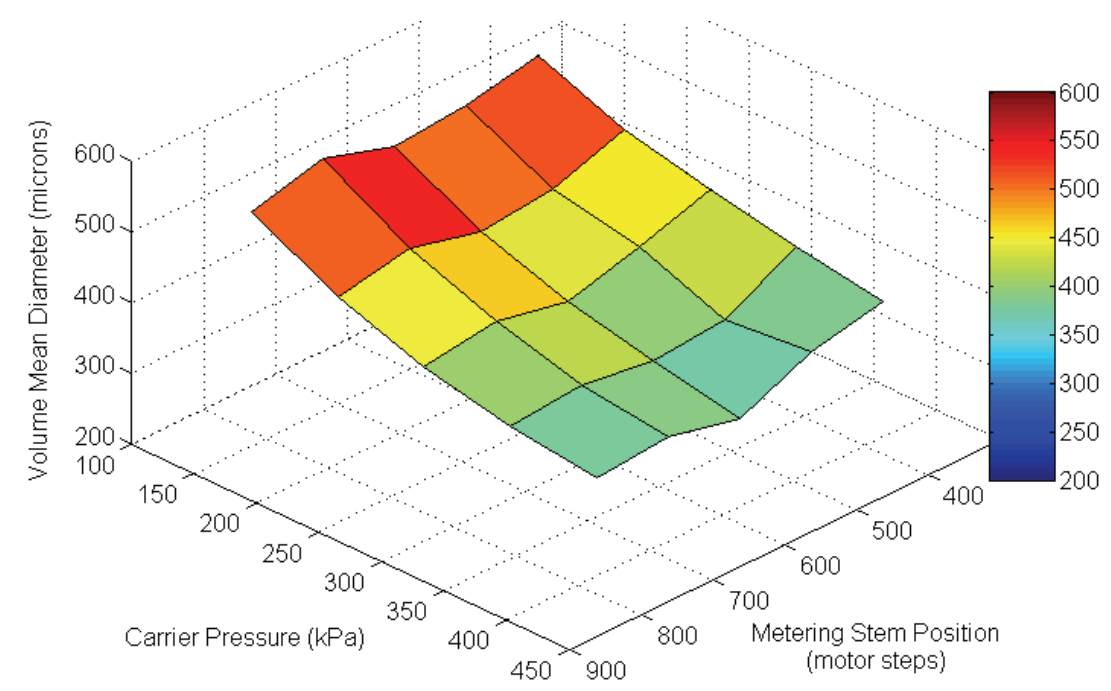

Figure 8. Average droplet spectra $\left(D_{\mathrm{v} 0.5}\right)$ versus metering stem position and carrier pressure.

the previously discussed effects of carrier pressure and metering stem position on the droplet spectra from the nozzle. Carrier pressure had a more pronounced inverse effect on the droplet spectra as pressure increased from 138 to $414 \mathrm{kPa}$. The metering stem position did not have as pronounced an effect on $\mathrm{D}_{\mathrm{v} 0.5}$ values.

\section{CONCLUSiOnS}

Tests were conducted to evaluate the discharge characteristics of the variable-orifice nozzle with the goal of developing an acceptable operating envelope for the nozzle. Specifically, flow rate, spray pattern, and droplet spectra characteristics were assessed at five carrier pressures and five metering stem positions.

Flow rate tests indicated turndown ratios of approximately $2.4: 1$ for each operating pressure, with a turndown ratio of 4.8:1 across the carrier pressure range tested. Maximum flow rates were approximately $4.14 \mathrm{~L} \mathrm{~min}^{-1}$ (at $414 \mathrm{kPa}$ ) with minimum flow rates of $0.86 \mathrm{~L} \mathrm{~min}^{-1}$ (at $138 \mathrm{kPa}$ ) for all carrier pressures.

Spray pattern CVs were determined for nozzle spacings of 38.1 and $51.0 \mathrm{~cm}$. CVs were considered acceptable
$(<15 \%)$ for pressures ranging from 138 to $414 \mathrm{kPa}$ and metering stem positions of 400 to $800 \mathrm{MS}$ at nozzle spacings of 38.1 and $51.0 \mathrm{~cm}$. Spray pattern CVs improved when the nozzle spacing was decreased to $38.1 \mathrm{~cm}$.

Droplet spectra tests indicated that carrier pressures affected $D_{\mathrm{v} 0.5}$ values to a greater degree than metering stem positions. The droplet spectra classification was extremely coarse for these tests, slightly higher than the manufacturer data, which reported a droplet spectra classification of very coarse for the nozzle cap selected.

These results demonstrate that an actively controlled variable-orifice nozzle operating at a constant carrier pressure may help solve issues associated with spray application errors. Potential nozzle flow rates could be further extended if carrier pressure control were added to the system. Spray pattern degradation caused by carrier pressure losses with fixed-orifice nozzles has been recognized as a contributor to spray application errors. Test results suggested that it may now be possible to optimize the spray pattern by selecting certain combinations of carrier pressure and orifice position (in this case, metering stem position). Essentially, for applications requiring a set rate, different options would be available to achieve a desired nozzle flow rate 
with an optimal spray pattern. Thus, spray uniformity could be maintained across the boom. The study presented here used only water as a carrier for evaluation of the proposed system. Further testing to estimate the potential effects of orifice wear from extended use and of chemicals or additives would provide valuable information regarding the expected useful life of the variable-orifice nozzle tip. Without a feedback loop to monitor flow versus pressure, nozzle tips would need to be checked to verify performance.

\section{ACKNOWLEDGEMENTS}

The authors would like to thank Dr. Erdal Ozkan, Mike Sword, Luke Brill, and Aaron Turner for their assistance in collecting the droplet spectra data during these experiments. This material is based on work supported by the USDA Cooperative State Research, Education, and Extension Service (CSREES) under Agreement No. 2009-07201146. Any opinions, findings, conclusions, or recommendations expressed in this publication are those of the authors and do not necessarily reflect the views of the USDA.

\section{REFERENCES}

ASABE. (2009). S572.1: Spray nozzle classification by droplet spectra. St. Joseph, Mich.: ASABE.

ASTM. (2006). E641-01: Standard methods for testing hydraulic spray nozzles used in agriculture. West Conshohocken, Pa.: ASTM.

Azimi, A. H., Carpenter, T. G., \& Reichard, D. L. (1985). Nozzle spray distribution for pesticide application. Trans. ASAE, 28(5), 1410-1414. http://dx.doi.org/10.13031/2013.32451.

Bui, Q. D. (1997). Design and development of a variable-flow fan nozzle using phase-partition air sampling for drift assessment. $\mathrm{PhD}$ diss. Knoxville, Tenn.: University of Tennessee, Department of Agricultural and Biosystems Engineering.

Bui, Q. D. (2005). VariTarget: A new nozzle with variable flow rate and droplet optimization. Paper No. 051125. St. Joseph, Mich.: ASABE.

Czaczyk, Z. (2012). Spray classification for selected flat fan nozzles. J. Plant Prot. Res., 52(1), 180-183. http://dx.doi.org/10.2478/v10045-012-0027-2.

Daggupati, N. P. (2007). Assessment of the VariTarget nozzle for variable-rate application of liquid crop protection products. MS thesis. Manhattan, Kans.: Kansas State University, Department of Biological and Agricultural Engineering.
Delavan. (2011). VariTarget variable flow rate nozzle. Mendota Heights, Minn.: Delavan AgSpray Products. Retrieved from www.delavanagspray.com/PDFs/VT-Flyer2007-Eng.pdf.

Dilawari, G., Taylor, R. K., Solie, J. B., \& Bennur, P. (2008). Nozzles for variable-rate fertilizer application. Paper No. 083732. St. Joseph, Mich.: ASABE.

Haan, C. T. (2002). Statistical Methods in Hydrology. Ames, Iowa: Iowa State University Press.

Han, Y. J., Bode, L. E., \& Hummel, J. W. (1986). Controlling chemical application rate with bypass spray nozzles. Trans. ASAE, 29(5), 1221-1227. http://dx.doi.org/10.13031/2013.30299.

Koo, Y. M., \& Kuhlman, D. K. (1993). Spray performance models of a designed swirl nozzle. Trans. ASAE, 36(3), 679-684. http://dx.doi.org/10.13031/2013.28385.

Kunavut, J., Schueller, J. K., \& Mason, P. A. C. (2000). Continuous control of a sprayer pinch valve. Trans. ASAE, 43(4), 829-837. http://dx.doi.org/10.13031/2013.2977.

Luck, J. D., Sama, M. P., Pitla, S. K., \& Shearer, S. A. (2010). Pneumatic control of a variable-orifice nozzle. Paper No. 1009618. St. Joseph, Mich.: ASABE.

Luck, J. D., Sharda, A., Pitla, S. K., Fulton, J. P., \& Shearer, S. A. (2011). A case study concerning the effects of controller response and turning movements on application rate uniformity with a self-propelled sprayer. Trans. ASABE, 54(2), 423-431. http://dx.doi.org/10.13031/2013.36445.

Ozkan, H. E., Reichard, D. L., \& Ackerman, K. D. (1992). Effect of orifice wear on spray patterns from fan nozzles. Trans. ASAE, 35(4), 1091-1096. http://dx.doi.org/10.13031/2013.28704.

Pontech. (1997). STP100 stepper motor controller board user's manual. Rancho Cucamonga, Cal.: Pontech.

Sharda, A., Fulton, J. P., McDonald, T. P., Zech, W. C., Darr, M. J., $\&$ Brodbeck, C. J. (2010). Real-time pressure and flow dynamics due to boom section and individual nozzle control on agricultural sprayers. Trans. ASABE, 53(5), 1363-1371. http://dx.doi.org/10.13031/2013.34891.

Sharda, A., Fulton, J. P., McDonald, T. P., \& Brodbeck, C. J. (2011). Real-time nozzle flow uniformity when using automatic section control on agricultural sprayers. Computers Elec. Agric., 79(2), 169-179. http://dx.doi.org/10.1016/j.compag.2011.09.006.

Womac, A. R. (2001). Atomization characteristics of high-flow variable-orifice flooding nozzles. Trans. ASAE, 44(3), 463-471. http://dx.doi.org/10.13031/2013.6101.

Womac, A. R., \& Bui, C. D. (2002). Design and tests of a variableflow fan nozzle. Trans. ASAE, 45(2), 287-295. http://dx.doi.org/10.13031/2013.8519. 